http://www.ejchem.net 2012, 9(2), 621-630

\title{
Removal of Chromium(III) Using Synthetic Polymers, Copolymers and their Sulfonated Derivatives as Adsorbents
}

\author{
FARAH KANWAL ${ }^{\mathrm{a}}$, MUHAMMAD IMRAN ${ }^{\mathrm{a}}$, LIVIU MITU ${ }^{\mathrm{b}}$, \\ ZEESHAN RASHID $^{\mathrm{a}}$, HUMA RAZZAQ ${ }^{\mathrm{a}}$, and QURAT-UL-AIN ${ }^{\mathrm{a}}$ \\ ${ }^{a}$ Institute of Chemistry, \\ University of Punjab, Lahore - 54590, Pakistan \\ ${ }^{\mathrm{b}}$ Department of Physics and Chemistry, \\ University of Piteşti, Pitesti-110040, Romania \\ ktm7ro@yahoo.com
}

Received 20 July 2011; Accepted 5 September 2011

\begin{abstract}
This study is concerned with the development of some synthetic polymers, copolymers and their sulfonated derivatives as adsorbents. The effectiveness of these adsorbents in removing $\mathrm{Cr}$ (III) from aqueous solution was evaluated by batch technique. The influence of different experimental parameters on removal process such as solution $\mathrm{pH}$, contact time, adsorbent dose, $\mathrm{Cr}$ (III) concentration and temperature were evaluated. Adsorption equilibrium was achieved in 20 to $30 \mathrm{~min}$. at $\mathrm{pH}>5$. The Langmuir, Freundlich and Temkin adsorption isotherms were used to elucidate the observed sorption phenomena. The maximum $\mathrm{Cr}(\mathrm{III}) 37.8 \mathrm{mg} / \mathrm{gram}$ of PS(polystyrene) and $37.2 \mathrm{mg} / \mathrm{g}$ of SAN (styrene/acrylonitrile copolymer) was removed as evaluated from Langmuir isotherm while the heat of sorption was in the range $0.21-7.65 \mathrm{~kJ} / \mathrm{mol}$ as evaluated from Temkin isotherm. It can be concluded that PS developed in this study exhibited considerable adsorption potential for application in removal of $\mathrm{Cr}$ (III) from aqueous media as compared to its copolymers and other derivatives used in this study.
\end{abstract}

Keywords: Chromium, Adsorption, Isotherm, Polymer.

\section{Introduction}

Chromium is considered as a priority pollutant among all the heavy metals. Various industrial effluents from pigments, electroplating, dying, canning, textile, leather tanning, paint, and steel industries contain substantial amounts of chromium. In general these industrial effluents contain both $\mathrm{Cr}(\mathrm{VI})$ and $\mathrm{Cr}(\mathrm{III})$ ions. Excessive buildup of $\mathrm{Cr}$ (III) ions can affect the ecological environment ${ }^{1}$. The importance to minimize the amount of $\mathrm{Cr}$ (III) ions in industrial effluents and other resources has diverted the interest of scientists towards 
selective adsorbents $\mathrm{Cr}$ (III) adsorption by different materials has been described elsewhere in the literature ${ }^{2-5}$. The commonly used methods for removing metal ion from aqueous waste include precipitation, lime coagula-tion, semisedimentation, electrodialysis, chemical reaction, biological process, ion exchange, filtration, reverse osmosis, solvent extraction, and common adsorption. The latter process being a more useful method for the metal ion removal than all other processes and is a consequence of surface energy ${ }^{4}$.

Various chemical modifications have been made on solid adsorbents to improve their physical and chemical properties and also to increase their cation exchange capacity. Application of chemical modification to increase the adsorption capacities of Polystyrene ${ }^{6}$, Polyaniline $^{7}$, Polypyrrole ${ }^{8}$, Polyacrylicester ${ }^{9}$, Poly(MMA-MAGA) ${ }^{10}$, Poly(GMA-Co-EDGMA)$\mathrm{en}^{11}$, XAD-4NDA-701 ${ }^{12}$, Polystyrenedivinylbenzene ${ }^{13}$ has been reported in the past. Keeping in view the importance of these chemical modification as applied in surface chemistry, we have attempted the synthesis of adsorbents from polystyrene which were ultimately investigated as an adsorbents for the removal of $\mathrm{Cr}(\mathrm{III})$. This study was also further extended is to investigate the kinetic and equilibrium parameters of these synthesized materials for the removal of $\mathrm{Cr}$ (III) from aqueous solutions.

\section{Experimental}

All the chemicals used in this work were of analytical grade. All the monomers were redistilled under reduced pressure before polymerization except acrylic acid. Styrene and methylmethacrylate were washed first with $5 \%$ aqueous sodium hydroxide followed by distilled water until it was neutral ${ }^{14}$. Acrylonitrile was washed with dilute sulfuric acid $(50 \%$ $\left.\mathrm{H}_{2} \mathrm{SO}_{4}\right)$ followed by dilute sodium carbonate solution $\left(4 \% \mathrm{Na}_{2} \mathrm{CO}_{3}\right)^{15}$. Deionized water was used to prepare all the solution in the study. IR spectra of all the adsorbents were recorded with IR Prestige-21-Shimadzu FTIR spectrometer using Nujol method. HANNA digital pH-meter (Model-8417) was used for $\mathrm{pH}$ adjustment. Perkin Elmer Atomic absorption spectrometer (Model-AA100) was used for the determination of chromium concentrations in the solutions.

\section{Adsorbents}

All the adsorbents used for the removal of $\mathrm{Cr}(\mathrm{III})$ were prepared synthetically.

\section{Preparation of PS, PAN, PMMA, PAA}

Microspheres of these polymers [poly(styrene)(PS), poly(acrylonitrile) (PAN), poly(methylmethacrylate)(PMMA), and poly(acrylicacid)(PAA)] were prepared by taking monomer of each $(23.0 \mathrm{~g})$ by emulsifier-free emulsion polymerization using ammonium persulfate (APS) as the initiator. The reaction was carried out in the nitrogen atmosphere at $70{ }^{\circ} \mathrm{C}$ under mechanical stirring at $350 \mathrm{rpm}$. The resulting polymer microspheres were purified by repeating filtration of the latex.

\section{Preparation of SAN, SMMA, SAA}

Styrene/acrylonitrile copolymer (SAN) microsphere was prepared by copolymerization of styrene $(20.0 \mathrm{~g})$ with acrylonitrile $(3.0 \mathrm{~g})$ by emulsifier-free emulsion polymerization using ammonium persulfate (APS) as the initiator. The reaction was carried out in nitrogen atmosphere at $70{ }^{\circ} \mathrm{C}$ under mechanical stirring at $350 \mathrm{rpm}$. The resulting copolymer microspheres were purified by repeating filtration of the latex ${ }^{16}$.

Styrene/methylmethacrylate copolymer(SMMA) and styrene/acrylicacid copolymer (SAA) were prepared according to the same procedure.

\section{Preparation of sulfonated adsorbents}

Sulfonatedpolystyrene (SPS) was prepared using a homogeneous reaction of a polystyrene (PS) solution in chloroform with a mixture of concentrated sulfuric acid $\left(\mathrm{H}_{2} \mathrm{SO}_{4} 98 \%\right)$ and 
phosphorous pentaoxide $\left(\mathrm{P}_{2} \mathrm{O}_{5}\right)$. The reaction was carried out at about $40{ }^{\circ} \mathrm{C}$ for $30 \mathrm{~min}$ with agitation ${ }^{17}$. Sulfonatedpolyacrylonitrile (SPAN), sulfonated styrene/acrylonitrile (SSAN), sulfonatedpolymethylmethacrylate(SPMMA),sulfonated copolystyrene/ methyl-methacrylate (SSMMA), sulfonatedpolyacrylicacid(SPAA), sulfonated- copolystyrene/acryli-cacid (SSAA) were prepared in the same way by using their suitable solvent i.e. dimethylsulfoxide (DMSO) and chloroform respectively.

\section{Particle size of adsorbents}

All the synthetic adsorbents were grinded to their minimum size. The minimum attainable size by these adsorbents is as follow; PS, PAN, SAN, PMMA, SMMA, SSMMA, SAA (100-110 mesh), SPS, SSAN, PAA and SPAA (200-210 mesh) while for SPAN, SPMMA and SSAA it was (250-260 mesh).

\section{Standard solutions}

Stock solution of chromium (1000 ppm) was prepared with appropriate weighed quantity of chromium(III) nitrate. Standard solutions of the desired concentrations (200-500 ppm) were obtained by successive dilutions of this stock solution. Deionized water was used to prepare all the dilutions.

\section{Effect of process parameters}

A series of experiments were carried out to study the effects of three parameters i.e. amount of adsorbate, $\mathrm{pH}$, and contact time on adsorption for the sample solution $(200 \mathrm{ppm}, 50 \mathrm{~mL})$. To study the effect of certain parameter, that parameter has been varied gradually keeping the other two constant. Measuring flasks $(100 \mathrm{~mL})$ were washed with deionized water and then dried in an oven at $105{ }^{\circ} \mathrm{C}$ for $30 \mathrm{~min}$. After adsorption under certain conditions, contents of the flasks were filtered and filtrate was subjected to Atomic Absorption Spectrophotometer for determination of chromium at $357.9 \mathrm{~nm}$ wavelength.

The effects of the $\mathrm{pH}$ was studied by varying the $\mathrm{pH}$ from 2 to $7(2,3,4,5,6$, and 7$)$. Fourteen measuring flasks were taken for sample solution. Synthetic adsorbent $(0.25 \mathrm{~g})$ was added to each and $\mathrm{pH}$ was adjusted by adding $\mathrm{HCl}(0.1 \mathrm{M})$ or $\mathrm{NaOH}(0.1 \mathrm{M})$ using $\mathrm{pH}$ meter. The flasks containing the adsorbent and solution were agitated on orbital shaker at $250 \mathrm{rpm}$ for $30 \mathrm{~min}$; solutions were filtered and analyzed to determine concentration of chromium. The effects of the contact time on $\mathrm{Cr}$ (III) adsorption was studied by varying the time of contact from 10 to $30 \mathrm{~min}(10,20$, and $30 \mathrm{~min})$. Sample solution was taken in fourteen measuring flasks. $0.25 \mathrm{~g}$ of synthetic adsorbent was added to each flask. $\mathrm{pH}$ of each sample was adjusted to 7 and agitated at $250 \mathrm{rpm}$ for different time intervals. After filtration, absorption for chromium was taken on atomic adsorption. The effect of the initial concentration of $\mathrm{Cr}(\mathrm{III})$ ion on the uptake by synthetic adsorbents was carried out by placing $0.25 \mathrm{~g}$ of synthetic adsorbent in a series of flasks containing $50 \mathrm{~mL}$ of $\mathrm{Cr}(\mathrm{III})$ ion at definite concentrations (200-500 mg/L) and $\mathrm{pH} 7$. The contents of the flasks were equilibrated on the shaker at $250 \mathrm{rpm}$ for $30 \mathrm{~min}$. After adsorption the residual concentration of the metal ion was determined. The data obtained from the adsorption experiments was used to calculate the adsorption capacity, $\mathrm{q}_{\mathrm{t}}(\mathrm{mg} / \mathrm{g})$ from Eq. (1):

$$
\mathrm{q}_{\mathrm{t}}=\left[\left(\mathrm{C}_{0}-\mathrm{C}_{\mathrm{t}}\right) / \mathrm{W}\right] \times \mathrm{V}
$$

Where $\mathrm{C}_{0}$ and $\mathrm{C}_{\mathrm{t}}$ are the concentrations of the $\mathrm{Cr}(\mathrm{III})$ in the solution before and after sorption respectively $\left(\mathrm{mg} / \mathrm{dm}^{3}\right), \mathrm{V}$ is the volume of the solution $\left(\mathrm{dm}^{3}\right)$ and $\mathrm{W}$ is the mass of the dry adsorbent (g). 


\section{Results and Discussion}

\section{Adsorbents characterization}

The change in chemical structure of various polymers as a result of copolymerization and functionalization was monitored by using FTIR spectroscopy. The FT-IR spectra of PS, SPS, PAN, SPAN, SAN and SSAN (Figure 1, a-f); PMMA, SPMMA, SMMA and SSMMA (Figure 2, g-j) were taken from $400 \mathrm{~cm}^{-1}$ to $4000 \mathrm{~cm}^{-1}$ and can be explained as follow;

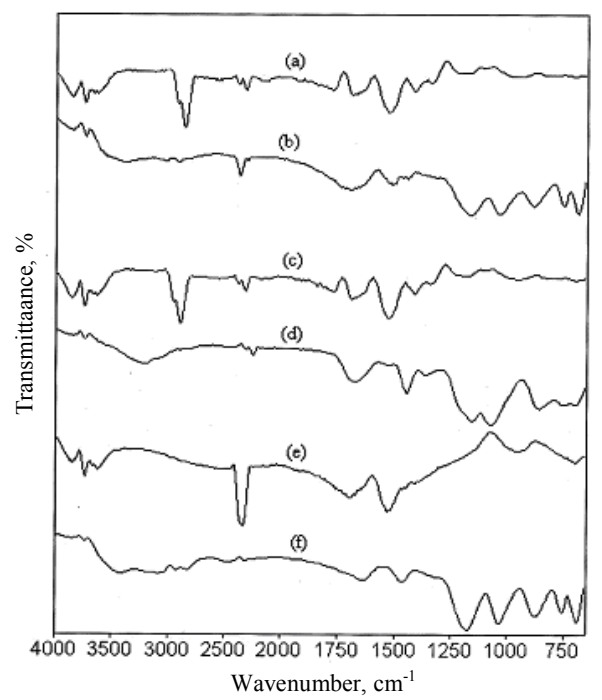

Figure 1. (a) PS (b) S-PS (c) PAN (d) S-PAN (e) SAN (f) S-SAN.

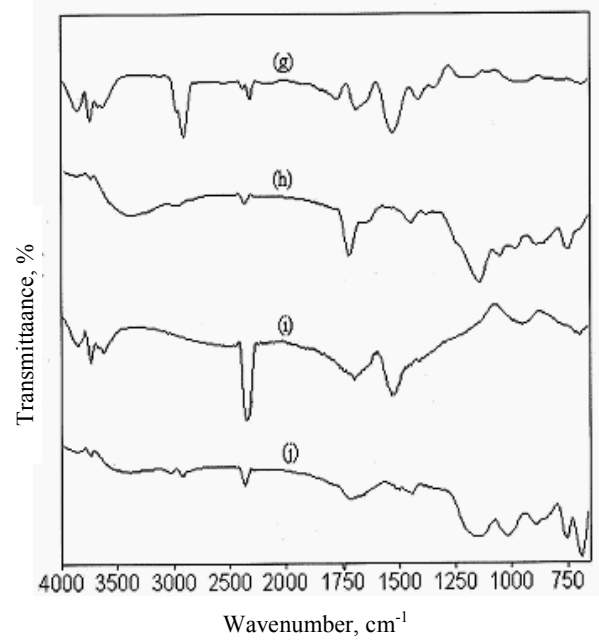

Figure 2. (g) PMMA (h) S-PMMA (i) SMMA (j) S-SMMA.

The FTIR spectrum of PS has characteristic peaks appearing at $3107 \mathrm{~cm}^{-1}, 2771 \mathrm{~cm}^{-1}$, $1523 \mathrm{~cm}^{-1}$ and $1411 \mathrm{~cm}^{-1}$ and are attributable to $\mathrm{C}-\mathrm{H}$ stretching vibrations, $\mathrm{CH}_{2}$ bending vibration, aromatic $\mathrm{C}=\mathrm{C}$ ring stretching vibration and $\left(\mathrm{CH}_{2}\right)$ group respectively ${ }^{18}$. The characteristic infrared absorbance's of SPS at $1033 \mathrm{~cm}^{-1}$ resulted from the symmetric 
stretching vibration of $-\mathrm{SO}_{3} \mathrm{H}$ groups while at $1163 \mathrm{~cm}^{-1}$ can be attributed ${ }^{19}$ to sulfonate anion attached to a phenyl ring (Figure 1-b). The characteristic bands for $\mathrm{C}-\mathrm{H}$ and $\mathrm{C} \equiv \mathrm{N}$ stretching vibrations of PAN were found at $2883 \mathrm{~cm}^{-1}, 2304 \mathrm{~cm}^{-1}$ respectively. Another band at $1413 \mathrm{~cm}^{-1}$ can be assigned to the $\mathrm{C}-\mathrm{H}$ bending mode. All three bands (Figure 1-c) are strong and support the presence of $\mathrm{PAN}^{20}$. Similarly the infrared spectrum of SPAN have been studied (Figure 1-d) which indicates the presence of sulfonic group at $1070 \mathrm{~cm}^{-1}$ while the absorption at $1155 \mathrm{~cm}^{-1}$ can be explained as resulted from a sulfonate anion attached to a $-\mathrm{CH}$ group. The IR spectrum of SAN (Figure 1-e) microspheres exhibited well-defined bands at about $947 \mathrm{~cm}^{-1}, 1529 \mathrm{~cm}^{-1}$ and $1691 \mathrm{~cm}^{-1}$ attributable to benzene ring of polystyrene while at $2347 \mathrm{~cm}^{-1}$ can be assigned to $-\mathrm{C} \equiv \mathrm{N}$ group ${ }^{21}$. The presence of these bands confirmed that the polymer microspheres are composed of styrene and acrylonitrile. For SSAN the absorption band at $1031 \mathrm{~cm}^{-1}$ can be assigned to symmetric stretching vibration of $-\mathrm{SO}_{3} \mathrm{H}$ groups and the absorption at $1172 \mathrm{~cm}^{-1}$ resulted from a sulfonate anion attached to a phenyl ring group (Figure 1-f).

Figure 2-g, shows the FTIR spectrum of PMMA with characteristic peaks at $2879 \mathrm{~cm}^{-1}$ $\left(\mathrm{CH}_{3}\right.$ stretching vibration), $2870 \mathrm{~cm}^{-1}\left(\mathrm{CH}_{2}\right.$ stretching vibration), $1772 \mathrm{~cm}^{-1}$ (carboxyl carbonyl stretching vibration) and $1687 \mathrm{~cm}^{-1}$ for carbonyl ${ }^{22}$ and suggest that the polymer microspheres are consisted of PMMA. The FTIR spectrum of SMMA microspheres revealed well-defined bands at about $947 \mathrm{~cm}^{-1}, 1529 \mathrm{~cm}^{-1}$ characteristic of the benzene ring of polystyrene and a characteristic peak of carbonyl group appearing at $1691 \mathrm{~cm}^{-1}$. The data confirmed that the polymer microspheres consisted of SMMA in Figure 2-i. The formation of SPMMA and SSMMA can be confirmed by observing their respective spectrum (Figure 2-h\&j) which indicates the presence of $-\mathrm{SO}_{3} \mathrm{H}$ groups at $\left(1049 \mathrm{~cm}^{-1}\right.$ $\left.\& 1012 \mathrm{~cm}^{-1}\right)$ and a sulfonate anion attached to $-\mathrm{CH}$ group or a phenyl ring $\left(1139 \mathrm{~cm}^{-1} \&\right.$ $\left.1136 \mathrm{~cm}^{-1}\right)$. The FTIR spectrum of PAA has characteristic peaks appearing at $1710 \mathrm{~cm}^{-1}$ was caused by the stretching vibration of the $\mathrm{vC}=\mathrm{O}$ in the carboxylic group of the PAA, a strong absorption band at $1523 \mathrm{~cm}^{-1}$ was observed which was assigned to the asymmetric vibration adsorption of the carboxylate group, $3606 \mathrm{~cm}^{-1}$ (OH stretching vibration), $2794 \mathrm{~cm}^{-1}$ (-CH stretching vibration). The data confirmed that the polymer microspheres consisted of PAA. The IR spectrum of SMMA microspheres revealed well-defined bands at about $947 \mathrm{~cm}^{-1}$, $1529 \mathrm{~cm}^{-1}$ characteristic of the benzene ring of polystyrene and a characteristic peak of carbonyl group appearing at $1691 \mathrm{~cm}^{-1}$. The data confirmed that the polymer microspheres consisted of SAA. The formation of SPAA and SSAA can be confirmed by observing their respective spectrum which indicates the presence of $-\mathrm{SO}_{3} \mathrm{H}$ groups at $1033 \mathrm{~cm}^{-1}$ and a sulfonate anion attached to a phenyl ring group or $-\mathrm{CH}$ group at $1157 \mathrm{~cm}^{-1} \& 1136 \mathrm{~cm}^{-1}$.

\section{Effect of $p H$}

Solution $\mathrm{pH}$ is an important factor controlling the surface charge of the adsorbent and the degree of ionization of the adsorbate in the solution ${ }^{23}$. The effect of the $\mathrm{pH}$ on $\mathrm{Cr}$ (III) adsorption was studied by varying the $\mathrm{pH}$ from 2 to 7 ; the results are shown in Figure 3. Graph exhibits that $\mathrm{pH}$ significantly affects the adsorption and maximum adsorption occurs at $\mathrm{pH}=7$. At $\mathrm{pH}>7$, insoluble chromium hydroxide starts precipitating from the solution, making true sorption studies impossible. So, it is concluded that $\mathrm{pH}$ of the solution should be acidic in order to get good results but should not exceed 7 . The adsorption phenomenon exhibited by PS is might be due to physical adsorption and $\pi-\pi$ dispersion forces. These are due to the presence of aromatic ring of styrene ${ }^{24,25}$ while SPS shows the adsorption due to the presence of $-\mathrm{SO}_{3} \mathrm{H}$ as an additional group as compared to PS shown in Figure 3. PAN shows adsorption due to the presence of $-\mathrm{C} \equiv \mathrm{N}$ group. This functionality is responsible for the uptake of metal cations by a chelation mechanism. Indeed, nitrogen atoms hold free 
electron doublets that can react with metal cations ${ }^{26}$ while SPAN shows adsorption due to the presence of $-\mathrm{SO}_{3} \mathrm{H}$ as an additional group as compare to PAN as shown in Figure 3.

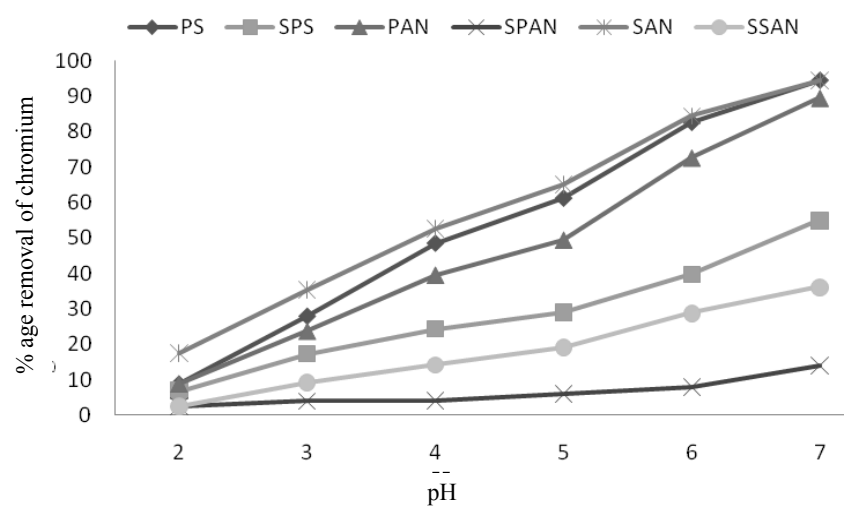

Figure 3. The effect of $\mathrm{pH}$ on adsorption of $\mathrm{Cr}(\mathrm{III})$ ions.

SAN shows adsorption due to the presence of aromatic ring of styrene (St) and nitrogen atoms of acrylonitrile (AN) present on the surface of the adsorbent while SSAN shows adsorption due to the presence of $-\mathrm{SO}_{3} \mathrm{H}$ as an additional group as compare to $\mathrm{SAN}$ as shown in Figure 3. Adsorption of $\mathrm{Cr}(\mathrm{III})$ increases with the increase of $\mathrm{pH}$ because at lower $\mathrm{pH}$ values competition exists between protons and metal ions for adsorption sites which decrease the adsorption capacity ${ }^{27}$. PMMA shows adsorption due to the presence of both carboxylate group oxygen and also due to physical adsorption of the PMMA latex ${ }^{28}$ while SPMMA shows adsorption due to the presence of $-\mathrm{SO}_{3} \mathrm{H}$ as an additional group as compare to PMMA shown in Figure 4.

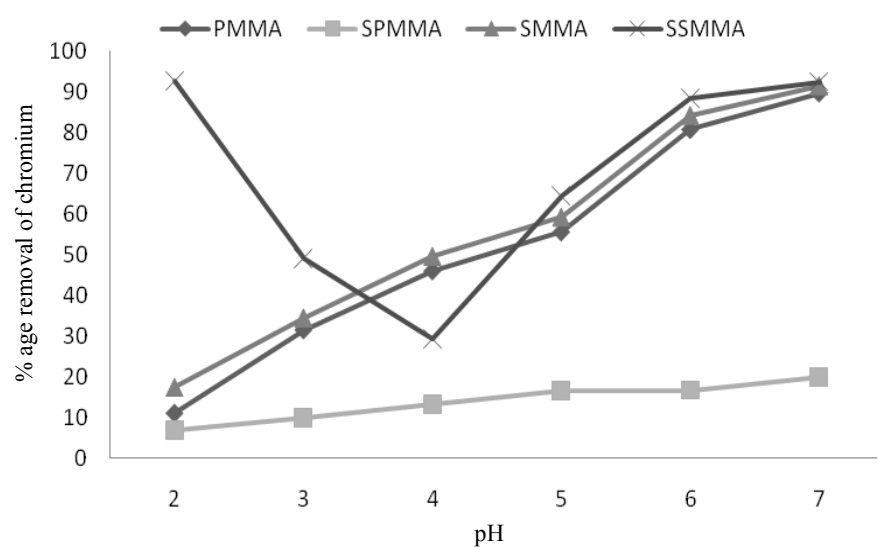

Figure 4. The effect of $\mathrm{pH}$ on adsorption of $\mathrm{Cr}(\mathrm{III})$ ions.

SMMA shows adsorption due to the presence of aromatic ring of styrene, carboxylate group oxygen of MMA present in the SMMA while SSMMA shows adsorption due to the presence of $-\mathrm{SO}_{3} \mathrm{H}$ group as an additional group as compare to SMMA. SSMMA shows maximum adsorption at $\mathrm{pH} 2$ due to complex formation with oxygen and at $\mathrm{pH} 7$ due to the $-\mathrm{SO}_{3} \mathrm{H}$ group because at lower $\mathrm{pH}$ competition exists between protons and metal ions for adsorption as shown in Figure 4. The carboxylate (- $\left.\mathrm{COO}^{-}\right)$group in the PAA is considered to be the active site for 
metal ion adsorption. At lower $\mathrm{pH}$ values, carboxylate ion in PAA is protonated and competition exists between protons and metal ions for adsorption sites which decreases the adsorption capacity at lower $\mathrm{pH}$ values ${ }^{29}$ while SPAA shows adsorption due to the presence of $-\mathrm{SO}_{3} \mathrm{H}$ group as an additional group present on the latex of adsorbent as shown in Figure 4. SAA shows adsorption due to the presence of carboxylate (-COO ${ }^{-}$group of AA and $\pi-\pi$ dispersion forces (due to the presence of aromatic ring) while SSAA shows adsorption due to the presence of $\mathrm{SO}_{3} \mathrm{H}$ group as an additional group present on the latex of SAA. SSAA shows maximum adsorption at $\mathrm{pH} 2$ due to the presence of carboxylate $\left(-\mathrm{COO}^{-}\right)$ion complex formation and attraction of aromatic ring which decrease with increase in $\mathrm{pH}$ because there is internal interaction between ions carboxylate $\left(-\mathrm{COO}^{-}\right)$and $\mathrm{H}^{+}$of $-\mathrm{SO}_{3} \mathrm{H}$ group as shown in Figure 5.

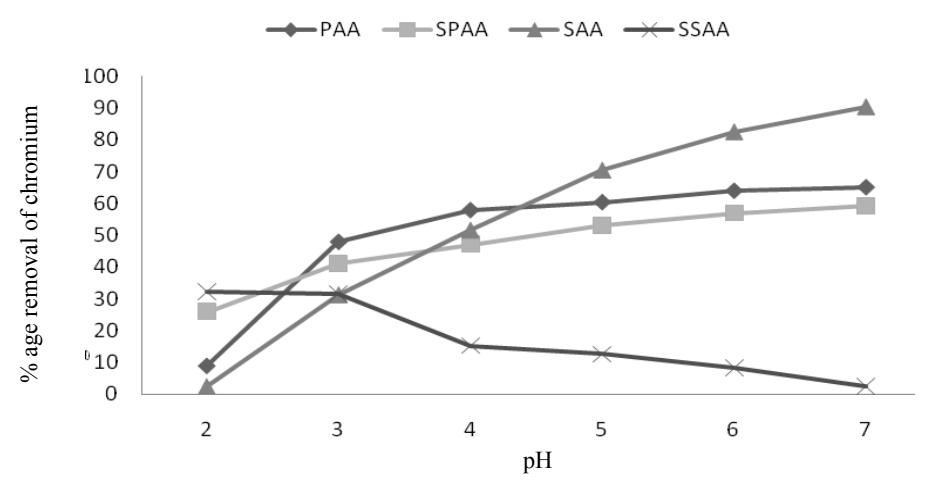

Figure 5. The effect of $\mathrm{pH}$ on adsorption of $\mathrm{Cr}(\mathrm{III})$ ions.

\section{Effect of metal ion concentration}

The effect of initial concentration of the metal ion uptake by adsorbents was conducted varying the metal ion concentration from $200-500 \mathrm{ppm}$ at $\mathrm{pH} 7$. The flasks were agitated on orbital shaker at $250 \mathrm{rpm}$ with the adsorbent dose of $5 \mathrm{~g} / \mathrm{L}$ for $30 \mathrm{~min}$. It was noticed that all these adsorbents show decrease in percentage removal of chromium because all the active sites are in limit and covered with $\mathrm{Cr}$ (III) as the concentration of $\mathrm{Cr}$ (III) is increased. All the adsorbent PS, SPS, PAN, SPAN, SAN, SSAN, PMMA, SPMMA, SMMA, SSMMA, PAA, SPAA, SAA and SSAA show maximum adsorption at $200 \mathrm{ppm}$.

\section{Effect of contact time}

The effect of the contact time on $\mathrm{Cr}(\mathrm{III})$ adsorption was studied by varying the time of contact from 10 to $30 \mathrm{~min}$ at $\mathrm{pH} \mathrm{7.} \mathrm{The} \mathrm{flasks} \mathrm{were} \mathrm{agitated} \mathrm{on} \mathrm{orbital} \mathrm{shaker} \mathrm{at} 250 \mathrm{rpm}$ with the adsorbent dose of $5 \mathrm{~g} / \mathrm{L}$ at concentration $200 \mathrm{ppm}$. Increase in removal efficiency with increase in time of contact is due to the fact that more time becomes available for metal ions to make a complex with adsorbents. Initial removal occurs immediately as soon as the metal and adsorbents came into contact, but after that when some of the easily available active sites become unavailable, metal needs time to find out more active sites for binding. It is concluded that metal and adsorbents i.e. SAN and SMMA should be in contact for at least 20min, while metal and adsorbents i.e. PS, SPS, PAN, SPAN, SSAN, PMMA, SSMMA, PAA, SPAA, SAA and SSAA should be in contact for at least $30 \mathrm{~min}$ in order to get good results. Adding more adsorbent will require less contact time to attain equilibrium. 


\section{Adsorption isotherms}

The Langmuir, Freundlich and Temkin isotherms were plotted according to Eqs. (2) - (4):

$$
\begin{gathered}
\mathrm{q}=\left[\mathrm{Q}_{\max } \mathrm{b} /(1+\mathrm{bCe})\right] \mathrm{Ce} \\
\mathrm{q}=\mathrm{K}_{\mathrm{f}}(\mathrm{Ce})^{1 / \mathrm{n}} \\
\mathrm{q}=\mathrm{K}_{\mathrm{T}} \ln (\mathrm{Ce})+\mathrm{b}_{\mathrm{T}}
\end{gathered}
$$

Where $q(\mathrm{mg} / \mathrm{g})$ is the amount of metal adsorbed per unit mass of adsorbent and $C_{e}(\mathrm{mg} / \mathrm{L})$ is the equilibrium concentration of adsorbate in solution after adsorption; $Q_{\max }(\mathrm{mg} \mathrm{Cr} / \mathrm{g}$ adsorbent) and "b" (Langmuir adsorption coefficient, a constant) are Langmuir parameters. $K_{f}$ is Freundlich adsorption coefficient, " $n$ " is empirical constant reflecting the heterogeneity of the surface sites and dependent on the nature of sorbent and sorbate; $b_{T}(\mathrm{~kJ} / \mathrm{mol})$ is Temkin adsorption potential of adsorbent and $K_{T}$ is the Temkin adsorption coefficient. The Langmuir, Freundlich and Temkin isotherms are used to calculate above parameters and the corresponding parameters are given in Table 1.

Table 1. Langmuir, Freundlich and Temkin adsorption isotherm parameters.

\begin{tabular}{cccccccccc}
\hline Adsorbents & \multicolumn{2}{c}{ Langmuir parameters } & \multicolumn{3}{c}{$\begin{array}{c}\text { Freundlich } \\
\text { parameters }\end{array}$} & \multicolumn{2}{c}{ Temkin parameters } \\
\hline & $\begin{array}{c}\mathrm{Q}_{\max }, \mathrm{mgCr} / \\
\text { g-adsorbent }\end{array}$ & $\mathrm{b}$ & $\mathrm{R}^{2}$ & $1 / \mathrm{n}$ & $\mathrm{K}_{\mathrm{f}}$ & $\mathrm{R}^{2}$ & $\begin{array}{c}\mathrm{b}_{\mathrm{T}} \\
(\mathrm{KJ} / \mathrm{mol})\end{array}$ & $\mathrm{K}_{\mathrm{T}}$ & $\mathrm{R}^{2}$ \\
\hline PS & 37.8 & 0.001 & 0.99 & 0.61 & 0.011 & 0.99 & 3.48 & 4.86 & 0.99 \\
\hline SPS & 22 & 0.006 & 0.99 & 0.46 & 0.18 & 0.98 & 0.21 & 1.16 & 0.98 \\
\hline PAN & 36.8 & 0.0013 & 0.98 & 1.44 & 0.034 & 0.99 & 0.51 & 1.25 & 0.99 \\
\hline SPAN & 2.6 & 0.016 & 0.99 & 0.42 & 0.142 & 0.99 & 1.14 & 0.42 & 0.98 \\
\hline SAN & 37.2 & 0.0011 & 0.97 & 0.23 & 63.14 & 0.98 & 6.31 & 6.79 & 0.96 \\
\hline SSAN & 7.3 & 0.012 & 0.99 & 0.24 & 12.98 & 0.99 & 1.2 & 2.53 & 0.99 \\
\hline PMMA & 29 & 0.004 & 0.98 & 0.67 & 0.044 & 0.97 & 1.10 & 0.10 & 0.97 \\
\hline SPMMA & 9 & 0.01 & 0.99 & 0.17 & 2.83 & 0.99 & 7.65 & 13.51 & 0.99 \\
\hline SMMA & 36.2 & 0.0014 & 0.98 & 1.05 & 0.69 & 0.98 & 1.63 & 2.86 & 0.99 \\
\hline SSMMA & 37.1 & 0.0011 & 0.99 & 0.54 & 2.48 & 0.99 & 1.57 & 2.4 & 0.98 \\
\hline PAA & 22.2 & 0.0058 & 0.96 & 0.43 & 11.37 & 0.99 & 0.98 & 1.63 & 0.99 \\
\hline SPAA & 7.2 & 0.012 & 0.98 & 0.33 & 0.38 & 0.98 & 4.58 & 5.51 & 0.99 \\
\hline SAA & 36.1 & 0.0015 & 0.99 & 0.18 & 1.64 & 0.99 & 0.53 & 0.96 & 0.96 \\
\hline SSAA & 5 & 0.014 & 0.97 & 0.34 & 0.30 & 0.98 & 1.17 & 2.07 & 0.99 \\
\hline
\end{tabular}

$Q_{\max }$ value for all the synthetic adsorbent are in the following order: $\mathrm{PS}>\mathrm{SAN}>$ SSMMA $>$ PAN $>$ SMMA $>$ SAA $>$ PMMA $>$ PAA $>$ SPS $>$ SPMMA $>$ SSAN $>$ SPAA $>$ SSAA $>$ SPAN. PS has higher value of $Q_{\max }$ and SPAN the least indicating PS has more active sites as compared to other adsorbents. Value of $R^{2}$ shows correlation or linear relationship. The Freundlich models indicate that SPMMA has more affinity towards Cr(III) than all other adsorbents. The smaller value of $1 / n$ indicates formation of relatively stronger bonds between $\mathrm{Cr}$ on active sites of SAA. The affinity of all adsorbent towards $\mathrm{Cr}$ (III) are as follows: SPMMA $>$ SAA $>$ SAN $>$ SSAN $>$ SPAA $>$ SSAA $>$ SPAN $>$ PAA $>$ SPS $>$ SSMMA $>$ PS $>$ PMMA $>$ SMMA $>$ PAN. The Temkin models indicate that SPMMA has 
formed strongest bond with $\mathrm{Cr}$ (III) than all other adsorbents. Values of $b_{T}<8$ indicate that bond formed between adsorbents and chromium is not very strong and is breakable in acidic conditions. High value of $b_{T}$ for SPMMA indicates formation of relatively stronger bond between chromium and SPMMA than other adsorbents. The order of bond strength between chromium and adsorbents are as follow: SPMMA $>$ SAN $>$ SPAA $>$ PS $>$ SMMA $>$ SMMA $>$ SSAN $>$ SPAN $>$ PMMA $>$ PAA $>$ PAN $>$ SAA $>$ PAN $>$ SPS .

\section{Conclusion}

The present study shows that PS, PAN, SAN, PMMA, SMMA, PAA and SAA were prepared by emulsifier-free emulsion polymerization and copolymerization and their sulfonated derivatives SPS, SPAN, SSAN, SPMMA, SSMMA, SPAA and SAA were prepared by homogeneous sulfonation. All the polymers, copolymers and their sulfonated derivatives were confirmed by FTIR analysis. All the synthetic products were used as an adsorbent for the removal of $\mathrm{Cr}$ (III). The amount of $\mathrm{Cr}$ (III) was found to vary with initial solution concentration, contact time and solution $\mathrm{pH}$. The contact time necessary to reach the equilibrium using SAN and SMMA are 20min and for PS, SPS, PAN, SPAN, SSAN, PMMA, SPMMA, SSMMA, PAA, SPAA, SAA and SSAA is 30min. The adsorption is found to be highly dependent on $\mathrm{pH}$. All the adsorbents show maximum adsorption at $\mathrm{pH} 7$ except SSMMA and SSAA that shows at $\mathrm{pH}$ 2. Therefore maximum removal i.e. $95 \%$ is shown by PS at $\mathrm{pH} 7$. Its found that physical adsorption, $\pi-\pi$ dispersion forces, ion exchange and chelation reaction take place in the $\mathrm{Cr}$ (III) ion removal. The equilibrium data was well described by Langmuir adsorption isotherms. The maximum $\mathrm{Cr}(\mathrm{III})$ removal was $37.8 \mathrm{mg} / \mathrm{g}$ of PS and $37.2 \mathrm{mg} / \mathrm{g}$ of SAN. Relatively stronger bonds are formed between SPMMA and $\mathrm{Cr}(\mathrm{III})$ as evaluated from Temkin isotherm.

\section{References}

1. Anwar J, Shafique U, Salman M, Zaman W, Anwar S and Anzano J M, J Hazard Mater., 2009, 171, 797.

2. Kratochvil D, Pimentel P F and Volesky B, Environ Sci Technol., 1998, 32, 2693.

3. Al-Asheh S and Duvnjak Z, Adv Environ Res., 1997, 1, 194.

4. Yavuz M, Gode F, Pehlivan E, Ozmert S and Sharma Y C, Chem Eng J., 2008, 137, 453.

5. Namasivayam C and Yamuna R T, Water Air Soil Pollut., 1999, 113, 371.

6. Wang Z, Bai R and Ting Y P, Ind Eng Chem Res., 2008, 47, 1861.

7. Eisazadeh H, J Appl Polym Sci., 2007, 104, 1964.

8. Eisazadeh H, Appl Sci J., 2008, 3, 10.

9. Pan B J, Zhang W M, Pan C, Qiu H, Zhang Q R, Zhang Q X and Zheng S R, Environ Sci Technol., 2008, 42, 7411.

10. Denizli A, Sanli N, Garipcan B, Patir S and Alsancak G, Eng Chem Res., 2004, 43, 6095.

11. Nastasovic A, Jovanovic S, Dordevic D, Onjia A, Jakovljevic D and Novakovic T, React Funct Polym., 2004, 58, 139.

12. Pan B C, Du W, Zhang W M, Zhang X, Zhang Q R, Pan B J, Lu L and Zhang Q X, Environ Sci Technol., 2007, 41, 5057.

13. Kunin R, Pure Appl Chem., 1976, 46, 205.

14. Shi Y, Wu Y, Haob J and Li G, Physicochem EngAsp., 2005, 262, 191.

15. Bamford C H and Jenkins A D, Proc R SocLond., 1953, 216, 515.

16. Wang P H and Pan C Y, Eur Polym J., 2000, 36, 2297.

17. Kucera F and Jancar J, Polym Eng Sci., 1998, 38, 783. 
18. Abbes I B, Bayoudh S and Baklouti M, J Poly Environ., 2006, 14, 249.

19. Martins C R, Ruggeri G and Paoli M D, J Braz Chem Soc., 2003, 14, 797.

20. Ji L, Saquing C, Khan S A and Zhang X, Nanotechn., 2008, 19, 1.

21. Hwan M Y and Choo D, J Appl Polym., 1999, 74, 2811.

22. Liu C, Bai R and Hong L, J Colloid Interf Sci., 2006, 303, 99.

23. Sakkayawong N, Thiravetyan P and Nakbanpote W, J Colloid Interf Sci., 2005, 286, 36.

24. Pengthamkeerati P, Satapanajaru T and Singchan O, J Hazard Mater., 2008, 153, 1149.

25. Demirbas A, Pehlivan E, Gode F and Gulsin T A, J Colloid Interf Sci., 2005, 282, 20.

26. Puoci F, Iemma F, Spizzirri U G, Cirillo G, Curcio M and Picci N, Am J Agri Bio Sci., 2008, 3, 299.

27. Chen C Y and Chen S Y, J Appl Polym Sci., 2004, 94, 2123.

28. Kocaoba S and Akcin G, Adsorpt Sci Technol., 2004, 22, 401.

29. Ishiduki K and Esumi K, Langmuir, 1997, 13, 1587. 


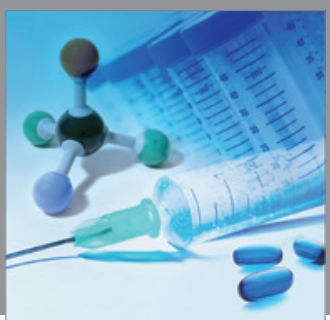

International Journal of

Medicinal Chemistry

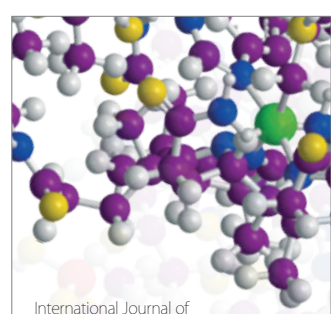

Carbohydrate Chemistry

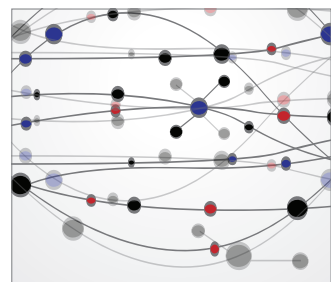

The Scientific World Journal
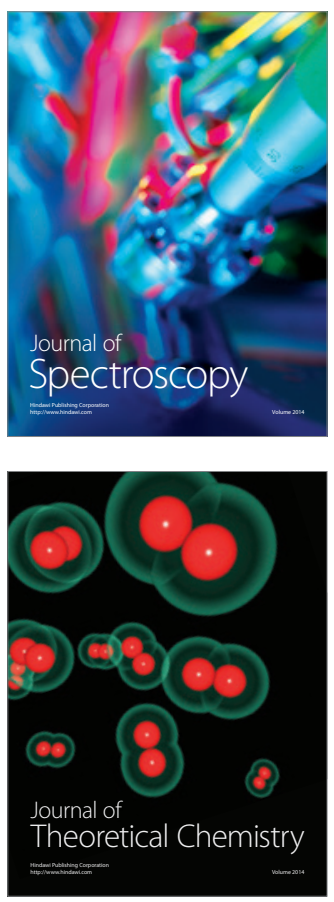
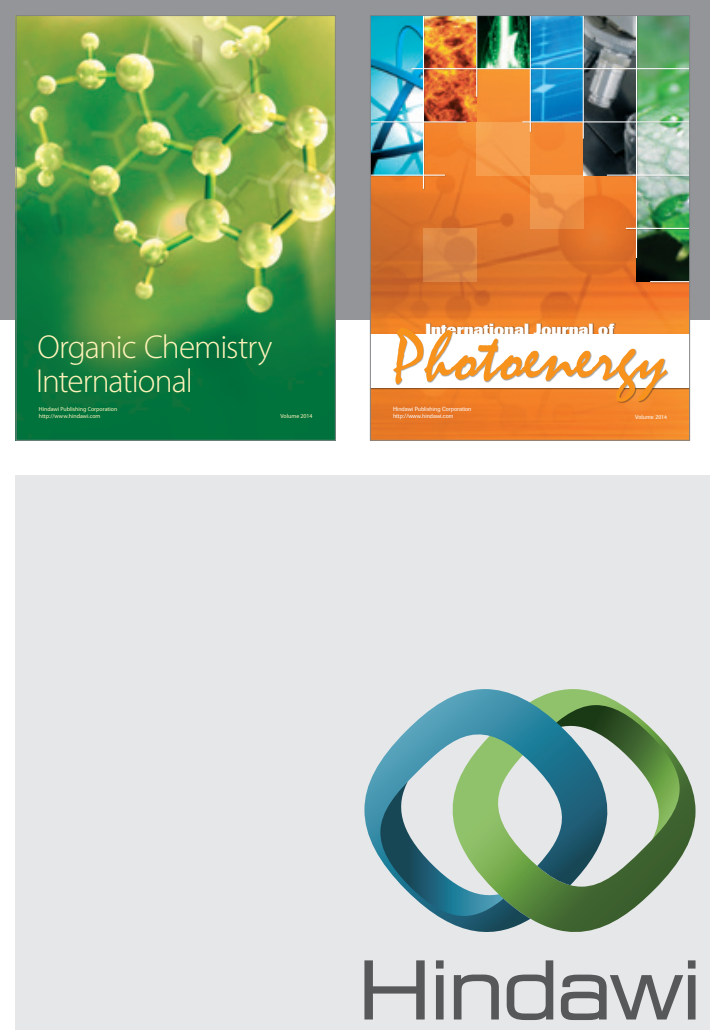

Submit your manuscripts at

http://www.hindawi.com
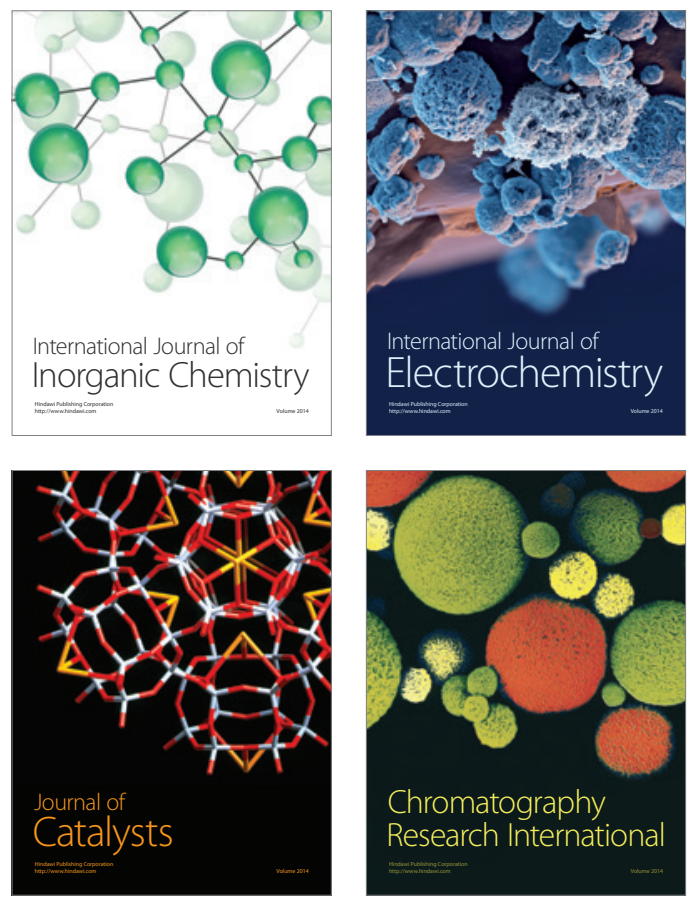
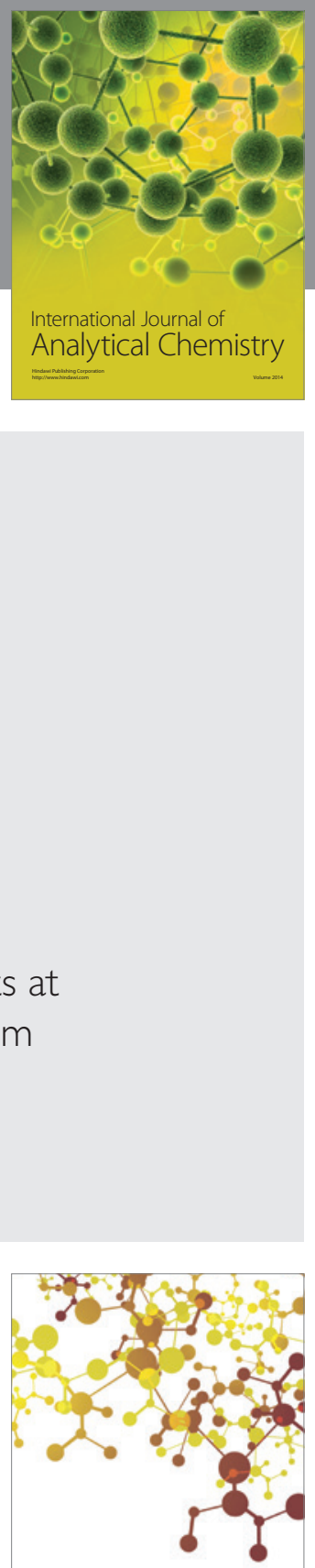

Journal of

Applied Chemistry
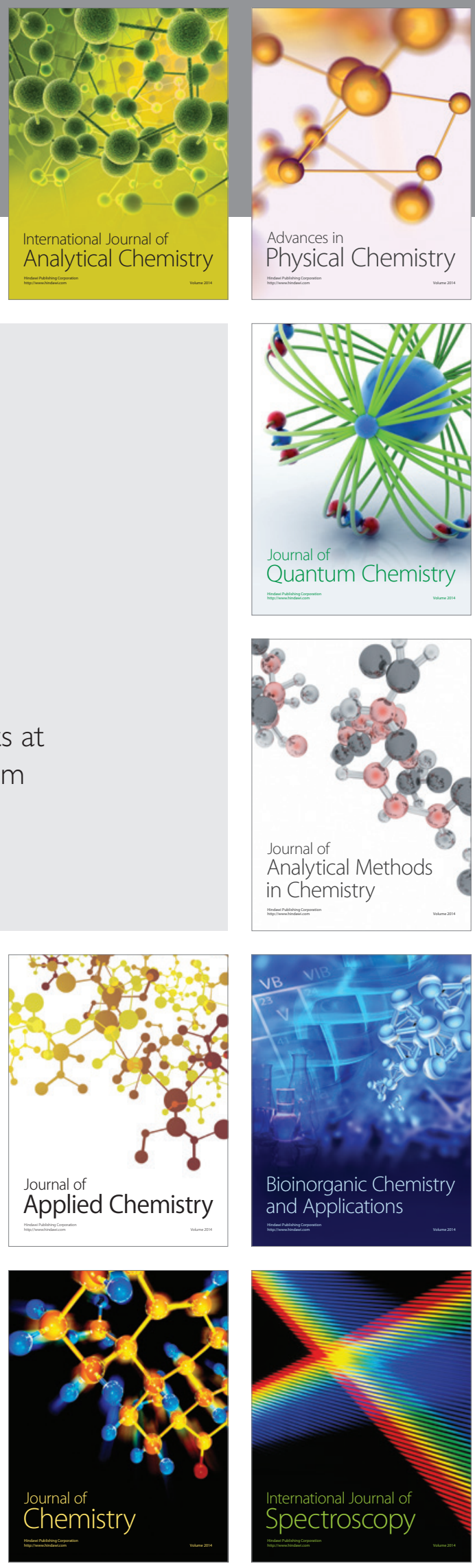